\title{
Do percurso de formação e desenvolvimento profissional: entre normas e (pre) conceitos para repensar a profissão docente
}

\author{
On the training and professional \\ development course: between norms \\ and (pre) conceptions to re-think \\ the teaching profession
}

Maria de Fátima Barbosa ABDALLA*

\begin{abstract}
RESUMO: O texto apresenta uma breve sistematização de aspectos conceituais que vêm norteando o percurso da formação e desenvolvimento profissional dos professores, com base nas diretrizes recentes elaboradas pela política educacional brasileira e no movimento dos educadores frente às tensões e desafios que foram desencadeados a partir dessas diretrizes. Sob essa perspectiva, o estudo retrata o contexto de formação docente, assinalando, do ponto de vista social e profissional, quais foram as mudanças mais significativas por que passaram e passam os professores. Ao denunciar os limites da real política de formação e profissionalização, este texto levanta considerações para repensar o compromisso do Estado e da Escola com o estabelecimento de políticas, assim como indica a necessidade de se valorizarem estratégias de aprendizagem da profissão, que permitam descortinar um percurso profissional de construção e de produção de sentido no conjunto das diretrizes propostas e das práticas educacionais.
\end{abstract}

Palavras-chave: formação e desenvolvimento profissional, política de formação e profissionalização, estratégias de aprendizagem da profissão

ABSTRACT: The text presents a brief systematization of the conceptual aspects that have been guiding the course of educator professional training and development based on the recent guidelines elaborated by the Brazilian educational policy and on the teacher movement when confronting the tensions and challenges that were triggered by

* Doutora em Educação pela Faculdade de Educação da USP. Professora do Programa de Pós-Graduação da Universidade Católica de Santos - UniSantos. E-mail: mfabdalla@uol.com.br

Olhar de professor, Ponta Grossa, 8(2): 11-25, 2005. 
such guidelines. From this perspective, the study pictures the context of educator training, marking from the social and professional points of view, the most significant changes teachers have gone and are going through. When denouncing the limits of the real training and professionalization policy, this text brings up issues to re-think the State's and the School's commitment to policy establishment, and indicates the need to value the profession's learning strategy in such a manner as to allow the revelation of a professional course of construction and production of meaning in the set of proposed guidelines and educational practices.

Key words: training and professional development, training and professionalization policy, profession's strategy

O mundo não é. O mundo está sendo. Como subjetividade curiosa, inteligente, interferidora na objetividade com que dialeticamente me relaciono, meu papel no mundo não é só o de quem constata o que ocorre mas também o de quem intervém como sujeito de ocorrências. Não sou apenas objeto da História mas seu sujeito igualmente. No mundo da História, da cultura, da política, constato não para me adaptar mas para mudar. (FREIRE, 1997, p. 85-86)

A história tem demonstrado que as mudanças pedagógicas não se fazem por decretos, normas e portarias. Elas são processuais e se constituem, no tempo, pela dinâmica da articulação entre a subjetividade (vontade de mudar) e a objetividade (condições objetivas para que as mudanças possam ocorrer). Pensar nessa articulação é necessário, na medida em que cada pessoa, em sua condição de sujeito, pode interferir na objetividade do mundo, não para adaptar-se, mas para mudar, como diz Paulo Freire.

Levando isso em consideração, objetiva-se, neste texto, refletir sobre alguns aspectos conceituais que vêm norteando o percurso da formação e desenvolvimento profissional dos professores, com base nas diretrizes recentes elaboradas pela política educacional brasileira e no movimento dos educadores frente às tensões e desafios que foram desencadeados a partir dessas diretrizes. Busca-se, assim, levantar alguns pontos que possam contribuir para o repensar de estratégias de aprendizagem para a profissão docente.

Sob essa perspectiva, pretendese destacar, primeiro, o contexto de formação e desenvolvimento profissional, assinalando-se, do ponto de vista social e profissional, quais foram as mudanças mais significativas por que passaram e passam os professores. Segundo, indicar, nesse quadro, alguns dos aspectos introdu- 
zidos, principalmente, pelas Diretrizes Nacionais para a Formação de Professores da Educação Básica (2001). Tais aspectos permitirão refletir sobre os princípios orientadores para a formação de professores. É importante ressaltar que a análise buscou como referência a legislação pertinente e as orientações propostas, examinandoas como possibilidades para a formação e desenvolvimento profissional do professor.

Em um terceiro momento, tem-se a intenção de pensar nas possíveis conseqüências e impactos que as referidas Diretrizes trazem, ou melhor, deixam de trazer para o processo de profissionalização, entendido, aqui, como aquele que pode possibilitar condições ideais para um exercício profissional de qualidade (LIBÂNEO, 2001). Algumas questões introduzidas pelo embate dos educadores serão então enfrentadas, abordandose o tema ora refletido na perspectiva da bibliografia já produzida. Serão denunciados, nesse momento, alguns dos limites da real política de formação e profissionalização, política essa que, entre normas e (pre)conceitos, vai-se constituindo em um poderoso instrumento de avaliação e certificação do complexo mundo do trabalho docente.

Finalmente, são tecidas algumas considerações no sentido de repensar o compromisso do Estado e da Escola com o estabelecimento de políticas que possam, efetivamente, melhorar as condições de formação e desenvolvimento profissional. Enfatiza-se o fato de que, nesse caminho, é preciso dar maior importância às estratégias que valorizem a aprendizagem da profissão dos professores, pois serão eles que orientarão as ações e reflexões no enfrentamento dos desafios/tensões da escola e da sala de aula, efetivando mudanças na realidade educacional.

\section{DOCONTEXTODE FORMAÇÃO E DESENVOLVIMENTO PROFIS- SIONAL: DESTACANDO ASPEC- TOS SOCIAIS E PROFISSIONAIS}

De fato, ao olhar para os professores que estão hoje no final de suas trajetórias profissionais, pode-se dizer que, nas últimas décadas, enfrentaram uma série de desafios e passaram por muitas mudanças. Do ponto de vista social, eles vivenciaram o período da ditadura militar (dos meados da década de 60 à década de 70), que gerou uma crise econômica, política e cultural muito intensa, na medida em que fortaleceu a reprodução acelerada da divisão de classes, o surgimento das multinacionais, o autoritarismo do governo e a repressão a toda espécie de manifestação da sociedade.

No final da década de 70 , no contexto da abertura política e da conseqüente democratização da sociedade, é que os educadores, de forma mais organizada, passaram a posicionar-se a favor de uma educação mais democrática, justa e igualitária, perceben- 
do a necessidade de fazer a ruptura com as formas do tecnicismo que eram tão fortes no governo anterior, autoritário e tecnocrático. A partir daí, foi possível revigorar a luta pela redemocratização, na perspectiva de superar as condições impostas pelo capitalismo, agravadas pelas políticas do Banco Mundial que, desde a década de 80, vem orientando o enxugamento dos recursos do Estado para a Educação.

É preciso mencionar, ainda, que mesmo no contexto dos anos 90, considerada a "década da educação" no momento atual, o que se percebe é o aprofundamento das políticas neoliberais e os incontroláveis efeitos da globalização, gerando um cenário nacional que, por vezes, torna mais complexo o mundo do trabalho dos profissionais da educação.

Do ponto de vista mais profissional, não se pode deixar de enfatizar, junto com autores como Nacarato, Varani, Carvalho (2001); Pimenta (2002); Dias Da Silva (2003) e Almeida (2004), entre outros, as múltiplas dificuldades/tensões que, apesar de todo esse tempo ter transcorrido, ainda estão mal resolvidas, tais como: a pre- cariedade das condições de trabalho; a massificação e o pauperismo em que se encontram as escolas, especialmente, as públicas; a desvalorização profissional e a degradação do status da profissão, agravada pelos baixos salários e pela falta de perspectivas de trabalho mais digno; os conteúdos que estão cada vez mais fragilizados, decorrentes de práticas fragmentadas; a cultura negativista e autoritária das escolas, apesar de anunciarem que participam de uma gestão democrática; e, por fim, os efeitos e as conseqüências de inúmeras legislações ${ }^{2}$, que ora mostram possibilidades para a ação dos educadores, ora rompem com essas mesmas possibilidades, e acabam por fortalecer uma política de aligeiramento tanto na formação inicial, quanto nas ações de formação continuada.

A partir dessa breve contextualização, torna-se importante e necessário analisar pelo menos um dos aspectos mencionados e as diferentes concepções e contradições que dele emanam, para repensar quais seriam as suas implicações na profissão docente. Nessa perspectiva, é relevante citar as Diretrizes Nacionais

\footnotetext{
${ }^{1}$ No período de 1993-1994, foi elaborado e divulgado o Plano Decenal de Educação para Todos, que deu início à reforma educativa brasileira. Tal Reforma seria mais amplamente proposta a partir da Lei de Diretrizes e Bases da Educação Nacional/LDBEN 9394/96.

${ }^{2}$ Entre elas, menciono a Lei de Diretrizes e Bases da Educação Nacional n 9394/96, que indica novos princípios de organização para a educação brasileira e introduz modificações significativas, especialmente, no âmbito da formação de professores. Este texto privilegiará as Diretrizes Nacionais para a Formação de Professores da Educação Básica (Parecer CNE/CP 009/2001), criadas a partir dessa legislação, pois elas delimitam o foco para o campo da formação de professores.
} 
para a Formação de Professores, que traduzem normas e (pre)conceitos ${ }^{3}$ específicos para orientar (e/ou desorientar) a prática docente, na medida em que abrem possibilidades e/ou delimitam reflexões/ações para o campo da formação e desenvolvimento profissional do professor.

Cabe esclarecer ainda, como discute Lopes (2004), que os sentidos da prática estão expressos nas propostas dos documentos oficiais, assim como as marcas desses discursos também estão inscritas na prática do cotidiano escolar. Isso significa dizer que, entre normas e (pre)conceitos, há uma produção de sentidos que está sendo desenvolvida e precisa ser compreendida e questionada. É com essa intenção que este texto se desdobra, procurando-se vislumbrar quais são as possibilidades e os limites colocados pela esfera oficial.

\section{DAS DIRETRIZES NACIONAIS PARAAFORMAC̃̃O DE PROFES- SORES: A VISÃO OFICIAL E OS PRINCÍPIOS DEFINIDOS COMO POSSIBILIDADES}

Partindo-se do pressuposto de que as políticas inscrevem marcas na formação e no desenvolvimento profissional dos professores, assim como o contrário pode e precisa acontecer, pretende-se, agora, com a releitura das Diretrizes Nacionais para a Formação de Professores (BRASIL, 2001), defender que há espaços de reinterpretação capazes de questionar e ressignificar a visão oficial e os princípios definidos por elas. Nesse sentido, as Diretrizes podem ser entendidas não somente como documento escrito, mas como aquele que pode ser vivenciado e reconstruído por outros sujeitos no corpo social da educação (LOPES, 2004, p. 111).

É importante assinalar, então, que as Diretrizes Nacionais para a Formação de Professores da Educação Básica pretendem construir uma sintonia entre a formação de professores, os princípios prescritos pela Lei de Diretrizes e Bases da Educação Nacional (LDBEN, 1996), as normas instituídas nas Diretrizes Curriculares Nacionais para a Educação Infantil, para o Ensino Fundamental e para o Ensino Médio e suas modalidades, bem como as recomendações constantes nos Parâmetros e Referenciais Curriculares para a Educação Básica, documentos elaborados pelo Ministério da Educação (BRASIL, 2001).

Em relação às mudanças promovidas pela LDBEN, é fundamental destacar que as Diretrizes retomam os seguintes aspectos:

a) integração da educação infan-

\footnotetext{
${ }^{3}$ Estou denominando de (pre)conceito todo aquele conceito que foi formulado previamente, no caso dos discursos legais, e que é aceito como idéia pré-concebida, não contestada pela maior parte dos educadores. De certa forma, são os conceitos definidos pelas Diretrizes Curriculares Nacionais, em questão.
} 
til e do ensino médio como etapa da educação básica, a ser universalidade; b) foco nas competências a serem constituídas na educação básica, introduzindo um paradigma curricular novo, no qual os conteúdos constituem fundamentos para que os alunos possam desenvolver capacidades e constituir competências; c) a importância do papel do professor no processo de aprendizagem do aluno; d) fortalecimento da escola como espaço de ensino e de aprendizagem do aluno e de enriquecimento cultural; e) flexibilidade, descentralização e autonomia da escola associadas à avaliação de resultados; f) exigência de formação em nível superior para os professores de todas as etapas de ensino; g) inclusão da Educação de Jovens e Adultos como modalidade no ensino Fundamental e Médio. (BRASIL, 2001, p. 7)

Diante disso, as referidas Diretrizes indicam como princípios norteadores para a formação de professores:

I - a competência como concepção nuclear na orientação do curso;

II - a coerência entre a formação oferecida e a prática esperada do futuro professor, tendo em vista: a) a simetria invertida, onde o preparo do professor, por ocorrer em lugar similar àquele em que vai atuar, demanda consistência entre o que faz na formação e o que dele se espera; b) a aprendizagem como processo de construção de conhecimentos, habilidades e valores em interação com a realidade e com os demais indivíduos, no qual são colocadas em uso capacidades pessoais; c) os conteúdos, como meio e suporte para a constituição das competências; d) a avaliação como parte integrante do processo de formação, que possibilita o diagnóstico de lacunas e a aferição dos resultados alcançados, consideradas as competências a serem constituídas e a identificação das mudanças de percurso eventualmente necessárias;

III- a pesquisa, com foco no processo de ensino e de aprendizagem, uma vez que ensinar requer, tanto dispor de conhecimentos e mobilizá-los para a ação, como compreender o processo de construção de conhecimentos. (BRASIL, 2001, p. 55)

Quanto aos aspectos acima mencionados, fica evidente o acento que as Diretrizes e os demais documentos legais colocam sobre: a) o aluno que se quer formar, capaz de mobilizar saberes em ação; e a concepção do professor, cuja principal tarefa é a de favorecer a construção da identidade e da autonomia de seus alunos, sejam eles crianças, jovens e adultos; b) as 
novas tarefas atribuídas à escola, na perspectiva de instaurar processos de mudanças em seu interior; e c) a necessidade de uma revisão profunda de aspectos essenciais da formação e desenvolvimento profissional dos professores, para que se compreenda a complexidade da profissão.

Será feita, a seguir, referência a cada um desses aspectos, buscandose destacar as possibilidades que as diretrizes propõem, não como normas jurídicas, mas enquanto expressão de práticas sociais. É utilizada a palavra possibilidades, na medida em que as Diretrizes oferecem instrumentos para os professores questionarem suas práticas pedagógicas e maneiras de ser e estar na profissão.

2.1 QUEALUNOSE DESEJAFORMAR? QUE PROFESSORES OS PROFISSIONAISQUEEXERCEMO MAGISTÉRIO DESEJAMSER?

Diante dos múltiplos desafios, uma das grandes questões que os professores enfrentam gira em torno do aluno que desejam formar. Ao se pensar nesse aluno e fazer a releitura dos princípios norteadores destacados pelas diretrizes, o que poderia ser mudado nas práticas pedagógicas desses professores? Ou, em outras palavras, quais poderiam ser as conseqüências/impactos das políticas educacionais no processo de profissionalização docente?

Pensando sobre isso, considera-se importante a reflexão individual e coletiva acerca de algumas das concepções apresentadas pelas Diretrizes. A partir de um processo de ressignificação desses conceitos postos em questão é que se podem abrir possibilidades de autonomia e de mudança nas práticas docentes.

\section{Qual a concepção de aprendizagem que os professores têm para o aluno que desejam formar?}

Segundo as Diretrizes (BRASIL, 2001), a concepção de aprendizagem passa pelo processo de construção de conhecimentos que se desenvolve no convívio humano, na interação entre o indivíduo e a cultura na qual vive, com a qual e para a qual se forma. Tal processo leva em conta as características individuais e as experiências de vida dos alunos na constituição de suas competências. $\mathrm{Ou}$ seja, não basta o aluno conhecer, ele tem que saber mobilizar conhecimentos em uma dada situação.

Como os professores vêm enfrentando as situações didáticas e as questões metodológicas para levar o aluno a aprender a realidade de forma efetiva, interativa e competente?

\section{Qual a concepção do conteúdo a se desenvolvido para que um aluno apren- da, construa conhecimentos e seja competente?}

Para que o aluno tenha uma aprendizagem significativa, é preciso que seja desafiado a aprender por situa- 
ções-problema que exijam reflexão e ação. Não se pode, portanto, infantilizar a educação dos alunos, no que se refere a conteúdos, métodos e processos.

É importante situar, ainda, que para as Diretrizes (BRASIL, 2001), os conteúdos são meio e suporte para a constituição das competências e devem, também, ser desenvolvidos em suas diferentes dimensões (BRASIL): a) conceitual - na forma de teorias, informações, conceitos; b) procedimental - na forma do saber-fazer; c) atitudinal - na forma de valores e atitudes.

Nas práticas pedagógicas hoje desenvolvidas, como os conteúdos são desenvolvidos? Os professores observam, refletem e registram o que fazem? Como as crianças, jovens e adultos ressignificam os conhecimentos de sala de aula?

Qual a concepção de avaliação que os professores pretendem, no processo de formação de jovens e adultos

Uma avaliação a serviço da seleção ou da aprendizagem? Uma avaliação que certifica pela excelência ou que tenta formar um cidadão crítico e consciente dos desafios do mundo contemporâneo?

Pretende-se uma avaliação que, vista como parte integrante do processo de formação desses jovens e adultos, possibilite: diagnosticar os problemas a serem superados em sala de aula, aferir os resultados alcança- dos, considerar as competências a serem constituídas e identificar mudanças de percurso quando necessário (BRASIL, 2001).

Dessa forma, avaliar não é só regular e acompanhar o conhecimento que está sendo adquirido, mas a capacidade de acioná-lo e de buscar outros conhecimentos para realizar o que está sendo proposto. Para isso, é preciso conhecer os critérios que estão sendo utilizados, analisar os resultados e os instrumentos de avaliação e auto-avaliação, de forma a tornar a avaliação uma prática cada vez mais transparente e coerente com o princípio educativo da formação humana.

Enfim, como é possível pensar a avaliação dos referidos alunos?

\subsection{COMOAESCOLAPODEABRIR POSSIBILIDADES DE MUDAN- ÇAS?}

Considerando-se que formar é orientar os indivíduos para o conhecimento e para as mudanças, a escola, como instituição social, precisa esforçar-se para abrir possibilidades de mudanças em suas próprias práticas. No entanto, não basta querer: é preciso buscar estratégias de mudanças que possam intervir, mudar a forma (a "cara") da escola. Para transformar a ação e a formação do professor, não bastam reformas impostas, mas há necessidade de se pensar em reformas compostas, portanto, compartilhadas pelo coletivo da escola. 
Há, nas escolas, espaços e tempos para discutir, por exemplo, as reformas que levam em conta as orientações do Ministério da Educação, dos Conselhos Educacionais ou das Secretarias da Educação? Como é que se dá o processo de negociação entre professores, direção e coordenação para abrir possibilidades de mudanças em nossa realidade educacional?

\subsection{QUAIS SÃO OS ASPECTOS ESSENCIAISDAFORMAÇÃOEDO DESENVOLVIMENTO PROFIS- SIONAL DOS PROFESSORES?}

Um dos aspectos principais para compreender a formação e o desenvolvimento profissional dos professores é entender que a prática do professor é o que ele traz de suas experiências: são os conhecimentos em situação. Conhecimentos que giram em torno das seguintes dimensões: a) de si mesmo (visão de mundo; filosofia pessoal; imagem e ritmo que pretende imprimir à realidade; rituais pedagógicos etc.); b) de seu meio (a relação com a classe; com seus pares; com a comunidade e com o contexto social mais amplo); c) da matéria de ensino (sob o ponto de vista científico e também pedagógico/didático); d) da organização e articulação curricular da escola; e) da gestão da escola e de seu projeto político-pedagógico.

Um outro aspecto essencial é compreender a complexidade do ato educativo, o qual passa pelo ensinar e aprender: um processo que possibi- lita conhecimento na ação. Tal processo precisa ser compreendido, interpretado e avaliado. Para isso, é preciso fortalecer a postura investigativa no âmbito das atitudes cotidianas.

Segundo as Diretrizes (BRASIL, 2001), é importante para a autonomia dos professores que eles saibam como são produzidos os conhecimentos que ensinam. Ou seja: é preciso que eles tenham noções básicas dos contextos e dos métodos de investigação usados pelas diferentes ciências, para não se tornarem meros repassadores de informações.

Se os professores assumirem a postura de investigadores de suas próprias práticas, necessitam, também, conhecer e saber usar determinados procedimentos de pesquisa: levantamento de hipótese, delimitação de problemas, registro de dados, sistematização de informações, análise e comparação de dados, verificação, entre outros. A partir desses instrumentos é que eles podem produzir e socializar o conhecimento pedagógico de modo mais sistemático, assim como atingir os alunos, provocando neles uma postura investigativa.

Como os professores podem fomentar, em si mesmos e em seus alunos, posturas investigativas diante da realidade? Como estruturar tempos e espaços, analisar e avaliar as suas práticas pedagógicas, possibilitar estratégias de mudanças e investir na própria formação e desenvolvimento profissional?

Partindo dos aspectos destacados 
(questões e/ou possibilidades) e da existência dos princípios norteadores para a formação de professores dispostos nas respectivas Diretrizes, é possível pensar, ainda que de forma breve, em algumas conseqüências e impactos dessas normas e (pre)conceitos no percurso de formação e de desenvolvimento dos professores (desde a implementação das Diretrizes em 2001 até o presente momento). Levando em conta tais questões e tendo por referência os autores que escreveram sobre essa temática, será apresentada, a seguir, uma breve síntese que busca denunciar o significado (e os limites) da real política de formação e profisssiona-lização docente.

3. DAS CONSEQÜÊNCIAS E IMPACTOS PARAA PROFISSIONALIZAÇÃO: OQUE DIZEMOSDIFERENTESEDUCADORES?

E depois das memórias vem o tempo trazer novo sortimento de memórias, até que, fatigado, te recuses e não saibas se a vida é ou foi. (Drummond de Andrade, na Rosa do Povo, 1964)

Um tempo já se passou, e depois das memórias, como diz o poeta, vem o tempo trazer novo sortimento de memórias. Nesse sortimento de memórias, o que dizem os educadores a respeito da implementação das políticas educacionais em questão? Quais têm sido as conseqüências e os im- pactos dos mencionados (pre)conceitos e normas? O que significa essa real política de formação?

Freitas (2004) vem analisando o movimento de produção das diretrizes de formação como um documento que materializa as concepções construídas oficialmente no campo da formação de professores, contrapondo a elas as concepções que vêm sendo construídas historicamente pelo movimento dos educadores. A autora indica alguns aspectos retomados neste estudo.

O primeiro deles é o conceito de competência, que, do ponto de vista perverso do capital, aproxima a área de educação e de formação de professores ao trabalho material (FREITAS, 2004). Tal relação reduz a formação ao caráter técnicoprofissionalizante. Nesse sentido, a primeira medida tomada pelo governo, indicada no Parecer CNE 115/99 (Brasil, 1999), foi a regulamentação dos Institutos Superiores de Educação (ISEs), como lócus de formação dos professores, deslocando-se, assim, a formação do âmbito acadêmico-científico das universidades e faculdades, para o de instituições de caráter técnico-profissional. A autora menciona, também, que essa "lógica das competências" enfatiza a individualização dos processos educativos e coloca para os professores a responsabilidade por sua formação e aprimoramento profissional.

Caracterizada, então, como um conjunto de habilidades de cada indi- 
víduo, a competência passa a ser critério do conceito de profissão e de sua conseqüente valorização. Segundo RAMOS (2001), isso significa dizer que uma gestão fundada na competência encerra a idéia de que um assalariado deve se submeter a uma validação permanente, dando constantemente provas de sua adequação ao posto, de seu direito a uma promoção ou a uma mobilidade promocional.

Pode-se considerar que o segundo conceito mais significativo, o qual está atrelado ao conceito de competências, é o conceito de simetria invertida. Nele, "o preparo do professor, por ocorrer em lugar similar àquele em que vai atuar, demanda consistência entre o que faz na formação e o que dele se espera" (BRASIL, 2001, p. 55). Segundo Freitas (2004), de acordo com o documento das Diretrizes, esse conceito - juntamente com o conceito de competências - passa a conformar as subjetividades, via formação de professores e educação das novas gerações, de modo a inseri-las na lógica da competitividade, da conformação/adaptação individual aos processos sociais e ao desenvolvimento profissional que se espera alcançar.

O terceiro conceito traduz-se na certificação de competências como um instrumento de avaliação. Entende Freitas (2004) que a adoção da certificação de competências, nas atuais condições do trabalho docente, contribuirá para aprofundar o quadro perverso caracterizado pela ausência de políticas de valorização e de formação continuada, pelas péssimas condições de funcionamento das escolas públicas e pela redução dos recursos para esse fim. Dessa forma, mais uma vez, o professor será responsabilizado pelo sucesso ou fracasso da escola e da educação pública.

Tais depoimentos abriram a perspectiva para uma análise mais crítica do modelo das competências, tomando como parâmetros a contextualização sociopolítica em que se dá sua implementação no mundo da educação e do trabalho. Apesar da crítica predominante dos educadores citados, é preciso destacar que as noções de competência, simetria invertida e certificação de competências (como instrumento de avaliação) podem ser vistas como preconceitos se forem desconsideradas a autonomia e a conscientização dos professores para superar suas limitações e identificar os verdadeiros entraves para uma ação conseqüente e transformadora da realidade.

Como conseqüências e impactos desses (pre)conceitos, o currículo brasileiro vem se relacionando diretamente a processos de avaliação e/ou sistemas de avaliação que são centralizados no âmbito do Ministério da Educação e se traduzem nos seguintes instrumentos de avaliação: Sistema Nacional de Avaliação da Educação Básica/SAEB, Exame Nacional de Ensino Médio/ENEM; Exame Nacional de Cursos/ENC, conhecido como 
Provão, que ora foi substituído pelo Exame Nacional de Desempenho de Estudantes/ENADE ${ }^{4}$. Tais instrumentos pretendem ocupar-se do desempenho dos estudantes em relação a competências, saberes, conteúdos curriculares e à formação em geral. Entretanto, é importante relatar que não dão conta de considerar todos esses aspectos - pelo menos, não na dimensão que se pretende - pois estão mais preocupados com os resultados do que com processos que levem à qualidade do aprendizado (LIBÂNEO, 2001).

Um outro ponto a destacar é que tais avaliações (exceto o antigo Provão) trabalham com amostras, o que não leva as escolas a se beneficiarem dos dados que puderam ser coletados (LIBÂNEO, 2001). Ou seja, quase nenhum impacto ou interferência tem no processo pedagógico desenvolvido no ambiente escolar.

Conforme aponta Freitas (2004, p. 96), há, ainda, um outro aspecto que torna mais cruel a relação do conceito de avaliação/certificação: são determinadas experiências brasileiras que estão dispondo (ou pensando dispor) recursos públicos para instituições melhor avaliadas (é o caso do SAEB, por exemplo) e/ou para professores que apresentem melhores resultados de experiências. Medidas como essas, que privilegiam o caminho da gratificação, reforçam o individualismo e a competitividade em diferentes segmentos da educação, aprofundam as diferenças e desarticulam a organização escolar e dos professores em seus locais de trabalho (FREITAS, 2004).

Os conceitos de competência, simetria e certificação/avaliação, ou melhor, esses (pre)conceitos delimitam e até podem negar as possibilidades que apontamos anteriormente. Traduzem, também, a real política de formação, regida pela necessidade de regulação do Estado, tal como afirma Freitas (2004). Política que, segundo a autora estabelece até mesmo os parâmetros orientadores dos modelos de formação e de instituições de formação que interessam ao país, reforçando, assim, uma lógica do mercado e desconsiderando as implicações sociais e humanas que se tem nesse processo.

Como conseqüência fundamental desta releitura, é preciso pensar em um trabalho a médio e longo prazo que prepare o educador para o enfrentamento diário desses impasses, levando-o a ressignificar os (pre)conceitos e as normas que são impostas e a valorizar, mais e melhor, o exercício de sua profissão.

Esse trabalho terá que passar, primeiro, pela reorientação do processo

${ }^{4}$ O ENADE, criado recentemente, faz parte integrante do novo Sistema Nacional de Avaliação da Educação Superior/SINAES, que tem por objetivo avaliar as instituições de educação superior e os seus respectivos cursos de graduação. 
de formação inicial e continuada, no sentido de repensar o percurso realizado pelos educadores e as mudanças que se pretende implementar junto com eles. Além disso, é preciso que ele se desloque para as escolas, pois é lá que se podem identificar as necessidades subjetivas e objetivas postas pela realidade educacional, analisar as proposições e as práticas, acompanhar os projetos em desenvolvimento e vislumbrar caminhos novos de profissionalização do magistério.

\section{CONSIDERAÇÕES FINAIS}

A mudança do mundo implica dialetização entre a denúncia da situação desumanizante e o anúncio de sua superação, no fundo, o nosso sonho. É a partir deste saber fundamental: mudar é dificil, mas é possível (grifos do autor), que vamos programar nossa ação político-pedagógica... (FREIRE, 1997, p. 88)

As diretrizes elaboradas pelas diferentes políticas educacionais e, especialmente, as Diretrizes Nacionais para a Formação de Professores da Educação Básica indicam possibilidades e limites de olhar a prática de forma diferente. Para transformá-la, porém, é preciso fortalecer a formação e o desenvolvimento profissional dos professores, pois são eles, que, de fato, orientarão ações e reflexões, provocando mudanças na realidade da escola.

O que fazer?

É necessário, de início, como diz Paulo Freire, acreditar que mudar é difícil, mas é possível. Tal perspectiva pode abrir um caminho a ser seguido, pensando-se na definição de novos métodos ou estratégias que assegurem, no caso, o estabelecimento de uma experiência formadora. Experiência que se constitua como produtora de sentidos e saberes.

Reconhecendo-se as especificidades das discussões realizadas pelos autores, comentadas anteriormente, cabe reiterar que é preciso analisar os aspectos conceituais e as diferentes contradições que deles emanam, porque traduzem as reais dimensões políticas às quais os professores estão subjugados cotidianamente. A partir disso, interessa ressaltar em que medida o Estado e a Escola podem contribuir para fortalecer, então, a formação e desenvolvimento profissional do professor.

No que se refere ao Estado, seria importante que melhorassem as condições para a formação inicial e permanente, formação essa que precisa de acompanhamento didático-pedagógico contínuo, efetivo e de qualidade, inovando e incentivando os professores. Nesse sentido, algumas ponderações são oportunas:

- Ruptura com a tarefa de gerir reformas educacionais de fora para dentro, e de cima para baixo, distante da realidade das escolas e dos atores que nela atuam.

Olhar de professor, Ponta Grossa, 8(2): 11-25, 2005. 
- Implementação de sistemas de informações descentralizados, permitindo o fluxo de dados entre as decisões do governo e o acompanhamento das ações por parte dos professores e de toda a comunidade escolar.

- Promoção das condições materiais e de trabalho das unidades escolares, incrementando recursos e meios que possam assegurar o efetivo trabalho docente.

- Incentivo à formação de redes múltiplas de experiências (estimulando a troca de informações entre os professores de diferentes unidades escolares.

- Estabelecimento de políticas que, efetivamente, possam contribuir com a formação e o desenvolvimento profissional dos professores, em busca de uma educação mais democrática e de melhor qualidade.

Por outro lado, a escola teria que propiciar, regularmente, um tempo para os professores discutirem as informações (inclusive os dispositivos legais), trocarem experiências, descreverem as situações didáticas, registrarem suas vivências e aprenderem a sua profissão.

Um caminho para isso seria o de valorizar estratégias de aprendizagem da profissão que permitam, no decorrer do percurso de formação e desenvolvimento profissional: a) explicitar (pre)conceitos e normas, representações e práticas dos professores; b) vivenciar formas de tratamento das diferentes informações; c) tomar consciência em torno da resolução de problemas, avaliando as conseqüências e os impactos; d) reconstruir saberes por meio da organização, articulação e análise dos projetos e dos processos de condução e regulação das ações.

Essa seria uma maneira de colocar em pauta, discutir, denunciar e superar muitos dos problemas que são impostos aos professores (ora por orientações legais, ora pela própria realidade).

Enfim, é preciso que os professores descortinem um percurso profissional de construção e de produção de sentido no conjunto das diretrizes propostas e das práticas educacionais, programando, assim, as suas ações político-pedagógicas, tal como enfatiza Freire (1997), na epígrafe apresentada no início destas considerações. Essa é uma tarefa árdua, mas não impossível, desde que haja vontade para mudar.

\section{REFERÊNCIAS}

ALMEIDA, M. I. O trabalho dos educadores. In: SILVA, A. M. M. e AGUIAR, M. A. da Silva (Orgs.). Retrato da escola no Brasil. Brasília: Confederação Nacional dos Trabalhadores em Educação, 2004, p. 105-118.

BRASIL. Conselho Nacional de Educação. Parecer CNE/CP 009/2001. Diretrizes Curriculares Nacionais para a Formação de Professores de Educação Básica, em nível superior, curso de licenciatura, 
de graduação plena. Brasília/DF: MEC, 08 de maio de 2001.

BRASIL. Conselho Nacional de Educação. Parecer CNE/CP 115/99. Diretrizes Gerais para os Institutos Superiores de Educação. Dispõe sobre os Institutos Superiores de Educação, considerados os arts. 62 a 63, da Lei 9.394/96, e o art. $9^{\circ}, \S$ 2, alíneas "c" e "h" da Lei 4.024/61, com redação dada pela Lei 9.131/95. Brasília/ DF: MEC, 10 de agosto de 1999.

DIAS DA SILVA, M. H. G. F. Projeto pedagógico e escola de periferia: viabilizar um sonho ou viver um pesadelo? In: MARINS, A.J., SILVA, A.M.M.; SOUZA, M.I.M. (orgs.). Situações didáticas. Araraquara: JM Editora, 2003, p. 119143.

DRUMMOND DE ANDRADE, Carlos. Obras completas. Rio de Janeiro: Aguiar Editora, 1964.

FREIRE, P. Pedagogia da autonomia: saberes necessários à prática educativa. 2 . ed. Rio de Janeiro: Paz e Terra,1997.

FREITAS, H. C. L. de. A formação inicial e continuada dos profissionais da educação. In: SILVA, A.M.M. e AGUIAR, M.A.da Silva (Orgs.). Retrato da escola no Brasil. Brasília: Confederação Nacional dos Trabalhadores em Educação, 2004, p. 81-104.

LIBÂNEO, J. C. Organização e gestão da escola: teoria e prática. 3. ed. Goiânia: Alternativa, 2001.

LOPES, A. C. Políticas públicas: continuidade ou mudança de rumos? Revista Brasileira de Educação, n. 26, 2004, p. 109-118.

PIMENTA, S. G. Professor reflexivo: construindo uma crítica. In: PIMENTA, S. G. GHEDIN, E. Professor reflexivo no Brasil: gênese e crítica de um conceito. São Paulo: Cortez, 2002, p. 17-52.

NACARATO, A. M. VARANI, A. CARVALHO, V. de. O cotidiano do trabalho docente: palco, bastidores e trabalho invisível... abrindo cortinas. In: GERALDI, C. M. G.; FIORENTINI, D. PEREIRA, E. M. A. (Orgs.). Cartografias do trabalho docente: professor(a)-pesquisador(a). Campinas: Mercado de Letras, 2001, p. 73-104.

RAMOS, M. N. A pedagogia das competências: autonomia ou adaptação? São Paulo: Cortez, 2001.

Encaminhado em: 20/03/05

Aceito em: 30/10/05

$$
\text { Olhar de professor, Ponta Grossa, 8(2): 11-25, 2005. } \overline{25}
$$

